Supplementary material for Sharma et al., BRCA-associated pancreatico-biliary neoplasms: Four cases illustrating the emerging clinical impact of genotyping. Acta Oncol 2015; doi: 10.3109/0284186X.2015.1044023.

\title{
Supplementary Appendix 1.
}

$\square$ Pancreatic cancer

Cancer of the breast

$\square$ Other cancer
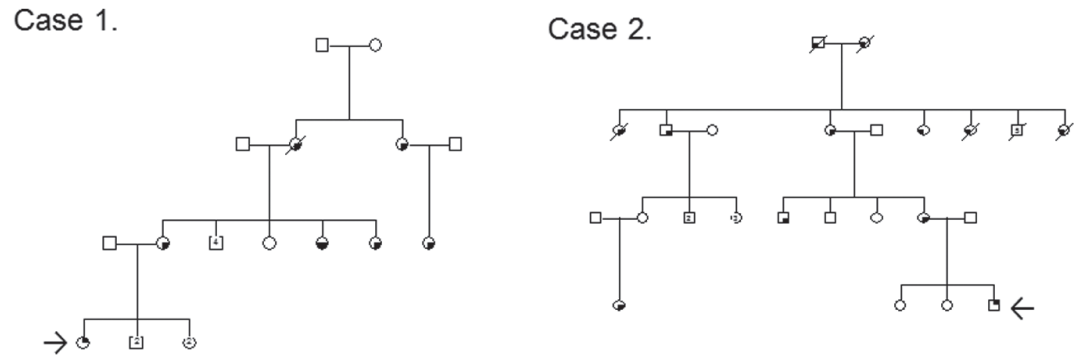

Case 3 .

Case 4.
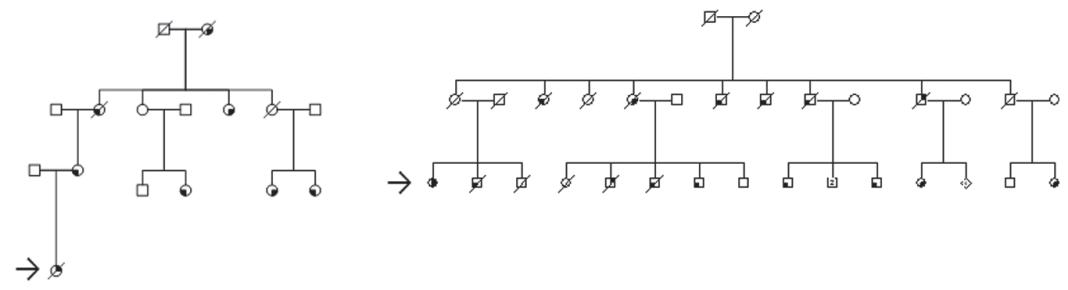

Family tree illustrating cancer history in the families of the 4 cases. Children of the index patients have been excluded as they are neither genetic tested nor diagnosed with cancer. Most of the the male cousins of case 4 with "other cancer" were diagnosed with prostate cancer. 